\title{
O UNIVERSO INFANTIL DE CLARICE LISPECTOR: UMA LEITURA DA ORALIDADE E DO FINAL ABERTO EM O MISTÉRIO DO COELHO PENSANTE
}

\author{
Cristina Rothier Duarte (UFPB) \\ Girlene Marques Formiga (UFPB)
}

Resumo: O Mistério do Coelho Pensante (1967), primeira obra de Clarice Lispector destinada ao público infantil, situa-se cronologicamente, no contexto historiográfico da literatura infantil brasileira, em uma fase marcada por duas principais vertentes: a constituída por produções que buscavam, sem sucesso, seguir o projeto de escrita lobatiana, e a formada por textos originais cujas temáticas giravam em torno da história, do folclore ou do maravilhoso, no entanto já possui marcas estilísticas características de obras publicadas a partir dos anos 70, tais como: o narrador não onisciente, a metaficção, o desfecho aberto, apenas para enumerar algumas características consideradas incomuns para a época. Diante disso, para este artigo, dedicamo-nos ao estudo da oralidade e do final aberto, elementos estéticos empregados pela autora considerados inovadores para o momento em que fora escrita e publicada.

Palavras-chave: Literatura Infantil e Juvenil; Clarice Lispector; Oralidade; Final Aberto.

Resumé: O Mistério do Coelho Pensante (1967), première œuvre de Clarice Lispector pour les enfants, se situe chronologiquement dans le contexte historiographique de la littérature de jeunesse brésilienne, dans une phase marquée par deux apsects principaux: celui constitué par les productions qui cherchaient suivre sans succès le projet d'écriture lobatienne, et celui formé de textes originaux dont les thèmes tournaient autour de l'histoire, du folklore ou du merveilleux, toutfois ses œuvres avaient déjà des marques stylistiques caractéristiques de celles publiées à partir des années 70 , comme: narrateur non omniscient, métafiction, fin ouvert, juste pour énumérer certaines caractéristiques considérées comme inhabituelles pour le moment. Par conséquent, pour cet article, nous nous sommes consacrés à l'étude de l'oralité et du fin ouverte, éléments esthétiques employés par l'auteur, considérés comme novateurs au moment de sa rédaction et de sa publication.

Mots-clés: Littérature pour enfants et adolescents; Clarice Lispector; Oralité; Fin ouverte. 


\section{INTRODUÇÃO}

Tratar da escritora Clarice Lispector, dentro do universo literário infantil, consiste em uma tarefa não muito simples, primeiramente, porque seu nome faz parte do cânone brasileiro no âmbito da conhecida literatura não adjetivada, e porque, de acordo com Bichuette e Coelho (2014), a crítica historiográfica da literatura infantojuvenil brasileira não tem conferido às suas obras o devido espaço a que thes cabe.

Neste artigo, todavia, tratamos de alguns aspectos formais identificados em O Mistério do Coelho Pensante, os quais outorgam qualidade à obra e nos fazem questionar o porquê, conforme as mencionadas pesquisadoras constataram, de as narrativas clariceanas infantis não receberem a devida atenção:

A historiografia literária, de modo geral, aborda a originalidade e a grandeza das obras de Clarice Lispector, além da linguagem e da versatilidade hermética da escritora, porém, pouca ou nenhuma atenção é dedicada à sua produção infantil, que não apenas precisa, mas merece ser estudada com profundidade no âmbito acadêmico com o objetivo de contribuir para a divulgação dessas obras e, também, para ampliar a fortuna crítica da autora. (BICHUETTE; COELHO, 2014, p.216)

Desse modo, compreendendo que existe a necessidade de concedermos um espaço de leitura e de discussão sobre 
a escrita clariceana infantil, trazemos a obra $O$ Mistério do Coelho Pensante, sob uma abordagem formal, mas que pode suscitar muitos outros vieses de estudo.

O Mistério do Coelho Pensante, assim, trata-se de um conto em que a narradora-personagem conta para Paulo a história do coelho Joãozinho que secretamente fugia de sua gaiola, sem que ninguém conseguisse saber como. Um enigma, então, é o mote empregado por Clarice Lispector para desenvolver a narrativa, utilizando-se de marcas estilísticas incomuns na literatura infantil brasileira da época, tais como a oralidade - diferenciada da presente nos contos populares - e o final aberto.

Verdade é que a escritora lança mão de um recurso, a história de animais, já empregado na tradição literária dirigida a crianças mediante as fábulas, no entanto, em $O$ Mistério do Coelho Pensante, temos as singularidades do coelho e do humano, as quais se contrapõem à antropoformização empregada como recurso para identificação do par personagem-leitor. Portanto, Joãozinho, na história, é um animal com características próprias de coelho, inclusive pelo fato de pensar em sua fuga:

Se você pensa que ele falava, está enganado. Nunca disse uma só palavra na vida. Se pensa que era diferente dos outros coelhos, está 
enganado. Para dizer a verdade, não passava de um coelho. 0 máximo que se pode dizer é que esse tratava de um coelho muito branco. [...] A coisa especial que acontecia com aquele coelho era também especial com todos os coelhos do mundo. É que ele pensava essas algumas ideias com o nariz dele. $O$ jeito de pensar as ideias dele era mexendo bem depressa o nariz.

(LISPECTOR, 1999, s/p.)

A inventividade da autora, então, parte de fatos simples e associados, em grande parte, à realidade. Não há fadas, bichos falantes, elementos mágicos, mas um coelho fugitivo que, de forma desconhecida, escapa da sua gaiola.

Guimarães (2017) expõe que, na obra, há o estímulo ao autoconhecimento do leitor, oportunizado por meio das comparações tecidas pela autora entre a natureza do animal e a da criança, mas não é apenas nesse aspecto que a narrativa de Clarice se diferencia das predominantes quando fora lançada. Nesse livro, e ainda em outros infantis de sua autoria, ela traz a oralidade com um caráter diferenciado, pois a narração cria "[...] uma relação de intimidade que se estabelece com os leitores, que têm Paulo [o personagem a quem a narradora se dirige] como porta-voz" (2017, p.106).

Além da oralidade sob o viés apontado, Clarice se utiliza, como tratamos no decorrer deste trabalho, do final aberto 
como mais um instrumento que endossa essa conversa íntima desenvolvida na narrativa, constituindo a presença de complicadores, até então, atípicos na literatura infantil nacional.

Posto isso, num primeiro momento, tratamos do contexto de produção da obra, a partir de informações reunidas em periódicos fluminenses, que circularam entre o final da década de 60 e início dos anos 70, consultados junto à Hemeroteca Digital Brasileira, para depois abordamos a oralidade e o final aberto, recursos empregados em $O$ Mistério do Coelho Pensante, os quais ora destacamos.

\section{O MISTÉRIO DO COELHO PENSANTE: COMO, QUANDO E POR QUÊ?}

Com uma consagrada carreira como escritora, no Brasil e no exterior, Clarice Lispector (1920-1977) ingressou, com a publicação de O Mistério do Coelho Pensante, em 1967, no universo ficcional em que se insere como "aparente" destinatário virtual o público infantil. Diz-se "aparente", visto que a autora, como ela mesma revelava, entendia sua escrita como dotada de independência quanto a uma delimitação de direcionamento em relação a um público específico, assim, embora obras como a mencionada sejam anunciadas pelo mercado editorial como infantis, na verdade são destinadas a qualquer leitor. 
O Mistério do Coelho Pensante, desse modo, é a primeira obra de uma série de cinco - A Mulher Que Matou os Peixes, Quase Verdade, A Vida Íntima de Laura, Doze Lendas Brasileiras - que permearam esse âmbito literário incerto no que diz respeito ao público de abrangência. Editada por José Álvaro e ilustrada por Eurídice, a obra nasceu, alguns anos antes, no seio familiar da autora, atendendo a um pedido de seu filho Paulo, quando tinha 6 anos de idade, e inspirado em um fato real:

Sentada no divã, máquina de escrever ao colo que é assim que ela compõe todos os seus livros, Clarice Lispector estava em meio ao original de A moça no Escuro, quando o filho Paulo - então com seis anos - fez o pedido, com um jeito que venceu todo propósito de adiamento; "Mamãe, escreve uma história para mim".

Saiu a fôlha pela metade, entrou outra em branco, foi nascendo assim a história dedicada ao menino e seu coelhinho O Mistério do Coelho Pensante - que a escritora vê como espécie de única filha, pois de um gênero ao qual jamais voltou, embora Ihe valesse um título de melhor de 67, pela Companhia Nacional da Criança.

"Depois eu escrevo, meu filho". A tentativa de adiamento foi repelida. "Não, mamãe, eu quero a história agora". Era a primeira vez que um dos filhos falava qualquer coisa sôbre o trabalho da escritora. Clarice - para não ficar longe das crianças - levava sempre a máquina de escrever para onde estivessem 
os filhos. Cada menino tinha um coelhinho. $O$ de Paulo - ninguém sabe como - conseguia fugir de uma jaula de ferro, com uma pesada tampa. Assim começou a história.

(DIÁRIO DE NOTÍCIAS, 1968, 4 fev., p.12)

Após escrita a narrativa, pelos idos de 1958, não foi publicada. Conforme uma matéria que circulou no Jornal fluminense Correio da Manhã, em 2 de novembro de 1971, a história consistia em poucas laudas que ficaram guardadas por longo período até que alguém, de cujo nome a autora não se lembrava, perguntou-lhe se não tinha algo infantil pronto para ser editado. "No primeiro momento, ela respondeu que não. Depois, se lembrou da história escrita quando estava em Nova York e foi só traduzir" (CORREIO DA MANHÃ, 1971, 2 nov., anexo, p.2).

No ano seguinte ao da publicação da primeira edição, O Mistério do Coelho Pensante foi laureado com o Prêmio Troféu Crianças, por ter sido considerado como um entre "Os melhores de 67", premiação que tinha como interesse, de acordo com uma publicação que circulou no Jornal do Brasil, em 31 de janeiro de 1968, estimular a produção artística destinada às crianças:

A Campanha Nacional da Criança divulgou ontem a lista dos Melhores da Criança em 1967, que inclui a escritora Clarice Lispector, o Teatro Tablado, o programa de TV Unidunitê 
e o ator Luis Fernando Ianeli. Êles receberão o Troféu Criança na sede do CEAT (Centro de Estudos e Atividades da Campanha), em data a ser fixada.

O concurso Melhores da Criança, realizado agora pela segunda vez, tem como finalidade estimular uma melhoria em todos os setores de atividades artísticas dirigidas ao público infanto-juvenil, segundo explicou a VicePresidente da Campanha, Dona Laura Pinto Guimarães.

(JORNAL DO BRASIL, 1968, 31 jan., p.17)

Em consonância com os periódicos fluminenses que circularam na época, Clarice Lispector pessoalmente resolveu observar a recepção da obra, apresentando-a a algumas crianças que foram colocadas diante do mistério das furtivas escapadas do coelho Joãozinho:

Clarice, agora que resolveu editar o livro escrito para seu filho, testou a reação de quatro crianças, de idades diferentes, sobre o mistério que o livro não desvenda e que vários adultos não conseguiram também entender.

A primeira criança, com cinco anos, disse que o coelho tinha patas tão fortes que levantava o tampo do engradado e saía. A segunda com sete anos [...], afirmou que o coelho era de papel e usava óculos. A terceira, com seus nove anos de idade, deu a explicação mais plausível - se é que o coelho se explica admitindo que o próprio filho de Clarice ajudava o coelho a fugir quando queria, sem que ninguém soubesse. Por fim, um menino 
de doze anos, filho da empregada da casa, contentou-se em lançar olhares fortuitos e a sorrir em cumplicidade, como se tivesse realmente desvendado o mistério do coelho pensante.

(JORNAL DO BRASIL, 1967, 30 out., p.2)

O interesse da escritora em conhecer como os pequenos leitores iriam reagir à sua obra, muito possivelmente, davase em razão do final aberto, tipo de desfecho ainda atípico naquele momento da literatura infantil brasileira, visto que, somente a partir dos anos 70, com o chamado boom, que passa a contar com esse tipo de final. Na obra, desvendar o mistério do coelho Joãozinho fica a cargo do leitor, de forma que este deverá dar resposta ao convite formulado pela autora:

Se você quiser adivinhar o mistério, Paulinho, experimente você mesmo franzir o nariz para ver se dá certo. É capaz de você descobrir a solução, porque menino e menina entendem mais de coelho do que pai e mãe. Quando você descobrir, você me conta. Eu é que não vou mais franzir meu nariz, porque já estou cansada, meu bem, de só comer cenoura. (LISPECTOR, 1999, s/p.)

Ademais, em O Mistério do Coelho Pensante, não há nem intuito edificante, nem concebe a criança como um destinatário de menor entendimento. "Nas obras infantis de Clarice Lispector não existe a aspiração de um saber, por isso, crianças e adultos podem se comunicar muito mais de 
perto e fazer parte de um mesmo universo." (BICHUETTE; COELHO, 2014, p.221). Nas palavras da autora:

Não tenho a pretensão de dar lições de moral para crianças, mas de mostrar-lhes certos erros que os adultos insistem em cometer. Aqui, escrever para crianças significava fazer pieguismo. Eu não gosto disso. Para alguém escrever para crianças deve também saber escrever para adultos. Não se deve rebaixar a criança, mas elevá-la.

(JORNAL DO COMMERCIO, 1973, 9 set., Segundo Caderno, p.5)

Como se vê, Clarice expressava ter uma visão atualizada da literatura infantil, equiparando-a à literatura "para adultos", o que repercutia em sua escrita. Além do final aberto, o caráter biográfico também estava presente em $O$ Mistério do Coelho Pensante. Conforme Guimarães, na obra são difusas as fronteiras entre a escritora Clarice Lispector e a narradora C. L.: "[...] a autora se apropria das histórias que vivenciou ao lado dos animais para aproximar-se do público infantil, no caso, os coelhos de seus filhos" (2017, p.105).

Além das mencionadas marcas estilísticas, a autora, em suas obras infantis, também emprega outros recursos, como a metalinguagem, a intertextualidade, não abordados nesta exposição, mas citados para demonstrar peculiaridades da escrita de Clarice para a infância, bem como a oralidade da qual passamos a tratar. 


\section{ORALIDADE: UM CONVITE AO LEITOR}

Os primórdios da literatura infantil estão intimamente relacionados à oralidade, característica fundamental dos contos de origem popular inicialmente destinados ao público adulto, mas que também alcançavam os mais jovens, em razão da ausência de distinção sociocultural entre ambos até o final do século XVII e início do século XVIII, quando surgiu uma nova concepção sobre o espaço social destinado à criança (DUARTE, 2019).

Da expressão oral, forma predominante de circulação dos contos populares, foram recolhidos e compilados em obras que se tornaram amplamente conhecidas, como Histórias da Mamãe Ganso ou Contos do Passado com Moralidades, publicada em 1697, por Charles Perrault (1628-1703), e Contos de crianças e do lar, de Jacob Ludwig Grimm (1785-1863) e Wilhelm Grimm (1786-1859), publicados em três volumes, entre os anos de 1812 e 1822. No começo, considerados "inapropriados" para as crianças, com o decorrer do tempo, tais contos foram adaptados ao que se considerava como gosto infantil, mediante a "higienização" de passagens violentas e dotadas de outras características compreendidas como inoportunas para as crianças.

Em O Mistério do Coelho Pensante, a oralidade, contudo, não traz suas marcas como as que estão presentes nos 
contos de origem popular, mesmo depois de adaptados para a infância, como o tom do contador de histórias e a adoção de elementos da própria fala, tendo em vista que, na obra de Clarice, "[...] encontramos um narrador que não somente conta uma história, mas que conversa com o leitor, e à medida que vai conversando vai contando a história e conduzindo a narrativa seguindo um fluxo metalinguístico na construção do enredo" (SOUSA, 2017, p.11).

A oralidade, então, assume, na narrativa clariceana, um aspecto inédito para a época: além do diálogo que trava com o personagem, abre espaço para o mediador tecer explicações no decorrer da contação como propõe a autora na apresentação da obra:

Como a história foi escrita para exclusivo uso doméstico, deixei todas as entrelinhas para as explicações orais. [...] Mas pelo menos posso garantir, por experiência própria, que a parte oral desta história é o melhor dela. Conversar sobre o coelho é muito bom. Aliás, esse "mistério" é mais uma conversa íntima do que uma história. Na verdade só acaba quando a criança descobre outros mistérios. (LISPECTOR, 1999, s/p.)

Vê-se, mediante a apresentação do livro, que a oralidade se amplia à forma tradicional, assumindo um viés de complementariedade à narrativa, o que significa que o leitor 
explicitamente é chamado à participação, seja por meio da imaginação da criança, seja representada pela mediação do adulto. Evidentemente, isso não constitui novidade para a literatura, contudo, na obra, o leitor é literalmente convocado para tanto. Em passagens, como: "Você na certa está esperando que eu agora diga qual foi o jeito que ele arranjou para sair de lá. Mas aí é que está o mistério: não sei!", "O que é que você acha que Joãozinho fazia quando fugia?" e "Desconfio que você não sabe bem o que quer dizer natureza de Coelho" (LISPECTOR, 1999, s/p.), a narração insere um espaço que confere vez ao leitor para dialogar, para perguntar e para construir.

Nas palavras de Guimarães, a narradora "[d]estituindo-se da posição do saber, convida a criança a refletir e a formular hipóteses sobre o fenômeno da fuga do coelho, dando a ela a chance de exercitar o pensamento [...]" (2017, p.105). De outro modo, Lajolo e Zilberman dizem que as obras infantis de Clarice "[...] trazem para a literatura infantil a perplexidade e a insegurança do narrador moderno" (1984, p.128), o que advém justamente dessa falta de onisciência por parte do narrador. Com efeito, a narradora não desvenda o mistério e lança o desafio para a criança e o adulto leitores, em conjunto, deslindarem o enigma do coelho que escapa de sua 
gaiola que é aparentemente à prova de fugas: "A casinhola tinha grades muito estreitas, e Joãozinho, além de branco, era gordo. É claro que não podia passar pelas grades. 0 único modo de se abrir a casinhola era levantando o tampo. E o tampo, Paulo, era de ferro pesado, só gente é que sabia levantar" (LISPECTOR, 1999, s/p.).

O desafio, no entanto, não é somente apresentado, pois na narração também é estabelecido um diálogo com o leitor igualmente revestido como hipóteses dos motivos para a fuga, a fim de compreender sua causa: "Às vezes penso que fugia para ver a namorada dele."; "Acho também que Joãozinho fugia porque cada vez ele tinha mais filhinhos e gostava de ir fazer carinho nos filhinhos."; "Às vezes também Joãozinho só fugia para ficar olhando as coisas, já que ninguém levava ele para passear." (1999, s/p.). As suposições e toda tessitura da obra, assim, são construídas ensejando um constante diálogo entre a criança e a narradora, o que para Diniz constitui um dos pontos altos da literatura infantil da autora:

A originalidade dos textos infantis de Clarice Lispector está em sua provocação ao leitor infantil enredando-lhe em enigmas que contribuem na elaboração de novos caminhos para o conhecimento. Ao renunciar ao ponto de vista hegemônico e omnisciente do narrador adulto e ao mostrar 
todas as suas hesitações e fragilidades, seus textos renunciam ao aspecto normativo tão presente na produção deste gênero de literatura para crianças. É o que parece ocorrer, por exemplo, em $O$ Mistério do Coelho Pensante. (2001, p.106-107)

É nessa provocação revestida de conversa, portanto, que se insere $O$ Mistério do Coelho Pensante, em que a criança é convidada a pensar nos mistérios da vida, da natureza humana metaforizados no enigma das escapadas de Joãozinho, o coelho branco e gordo.

Inseridos no seu projeto de escrita para a infância, há o que Lajolo e Zilberman (1984, p.155) chamam de "fragmentação" e "diluição na narrativa", o que significa dizer que Clarice adia e mesmo nega uma resposta para o enigma, requerendo do leitor a sua cooperação por intermédio de perguntas, como "Você não reparou que nariz de coelho parece estar sempre recebendo e mandando telegramas urgentes?" (LISPECTOR, 1999, s/p.), e da metalinguagem:

Paulinho, essa é uma verdadeira história de mistério. É uma história tão misteriosa que até hoje não encontrei uma só criança que me desse uma resposta boa. É verdade que nem eu, que estou contando a história, conheço a resposta. $\mathrm{O}$ que posso lhe garantir é que não estou mentindo: Joãozinho fugia mesmo. (LISPECTOR, 1999, s/p.) 
Frison (2014) entende a metalinguagem, em casos análogos a esse, como marcas da oralidade manifestadas nas interrupções que o narrador faz para falar da própria obra, pois, segundo o autor, a coerência da estrutura do discurso é "[...] restabelecida pelo faltante de forma mais imediata pela evocação do interlocutor" (p.291).

Outro recurso empregado por Clarice Lispector, na obra ora comentada, que se apresenta como objeto deste trabalho é o final aberto, do qual passamos a tratar a seguir.

\section{O FINAL ABERTO: DESVENDE O MISTÉRIO SE PUDER}

Desfecho, desenlace ou conclusão é o elemento da narrativa em que ocorre "[...] a solução dos conflitos, boa ou má, vale dizer configurando-se num final feliz ou não. Há muitos tipos de desfecho: surpreendente, feliz, trágico, cômico etc." (GANCHO, 2001, p.8). Como podemos perceber, a conceituação da pesquisadora não alcança os finais em que o desfecho fica a cargo do leitor, o final aberto.

Para Hila,

nesse esquema em que opera-se esse tipo de desfecho, a história normalmente inicia-se com uma situação de desequilíbrio inicial; segue-se a situação de desequilíbrio ou conflito; e, por fim, apresenta-se o final em aberto, em que o leitor, na verdade, assume um papel significativo, pois o desfecho pode sugerir várias possibilidades 
de encerramento, que não se apresentam definidas textualmente. (2004, s/p.)

Em O Mistério do Coelho Pensante, a narrativa segue a forma descrita. Logo no primeiro parágrafo do conto, a autora sinaliza que há um desequilíbrio: "Pois olhe, Paulo, você não pode imaginar o que aconteceu com aquele coelho" (LISPECTOR, 1999, s/p.), no entanto, estrategicamente, posterga a sua revelação. Antes de contar o ocorrido, o inimaginado, descreve o coelho, para somente doze parágrafos depois anunciar: "Como eu ia contando, Joãozinho começou a trabalhar na ideia. A ideia era a seguinte: fugir da casinhola todas as vezes que não houvesse comida na casinhola" (1999, s/p.).

Nos parágrafos seguintes, há a continuidade da problemática mediada por hipóteses sobre a causa das fugas do coelho, porém não se aventa, em nenhum momento, a forma como ocorriam, de modo que a grande questão não é respondida pelo texto e sua resolução fica aberta para o leitor.

O final aberto, segundo o entendimento de Colomer (2017), constitui-se como um complicador da literatura infantojuvenil e, na obra de Clarice, funciona como um dos aspectos de sua escrita os quais a afastam de estruturas narrativas mais simplificadas. O final aberto deixa "[...] sem 
explicitar uma parte da informação, esperando que o leitor deduza o que não foi dito [...]" (COLOMER, 2017, p.256), portanto, convoca efetivamente a sua participação para a construção do texto. Vejamos o desfecho de $O$ Mistério do Coelho Pensante:

Você me pediu para eu descobrir o mistério da fuga do coelho. [...]

Mas você sabe muito bem o que tem acontecido. Quando franzo o nariz, em vez de ter uma ideia, fico é com uma vontade doida de comer cenoura. E isso, é claro, não explica de que modo Joãozinho farejou um jeito de fugir das grades.

Se você quiser adivinhar o mistério, Paulinho, experimente você mesmo franzir o nariz para ver se dá certo. É capaz de você descobrir a solução, porque menino e menina entendem mais de coelho do que pai e mãe. Quando você descobrir, você me conta. Eu é que não vou mais franzir meu nariz, porque já estou cansada, meu bem, de só comer cenoura. (LISPECTOR, 1999, s/p.)

Clarice Lispector, adotando a ludicidade em sua narrativa, deixa a cargo do leitor, com o uso da imaginação, desvendar como o Joãozinho escapava da sua gaiola. A estética empregada pela autora apresenta-se, também nesse aspecto, inovadora dentro do contexto da literatura infantil brasileira da época. A maioria das obras que circulavam no período em que foi escrita (1958) apresentavam desfechos 
bem-acabados e felizes, desse modo, por mais que conflitos se fizessem presentes nas narrativas, no final haveria uma solução e tudo acabaria bem.

O final aberto, como ensina Colomer (2017), pode apresentar variados graus, no entanto, para assim ser considerado, "[...] deve afetar aspectos substanciais da obra [...]" (p.262). Segundo a autora, esse tipo de desfecho pode ser usado para mostrar uma visão mais completa da realidade; para conferir verossimilhança a narrativas que tratam de temas sociais; ou simplesmente compõe o jogo literário. Acerca do último tipo, comenta a autora:

Os finais mais nitidamente abertos são os que não se propõem a tratar questões morais, senão que perseguem unicamente o jogo literário. As obras que se baseiam no humor e na imaginação tendem a ampliar o jogo com expectativas do leitor para além do final do conto. Frequentemente o deixam sorridente ou esperançoso, sem poder precisar o que aconteceu ou não na história que acaba de terminar, ou bem deixam que decida o seu final. (COLOMER, 2017, p.263)

É justamente o que propõe Clarice na obra em estudo, prorrogar a ludicidade narrativa e provocar a criatividade do leitor, fazendo pensar em possíveis métodos de fuga e, consequentemente, finais viáveis para a história. Segundo Souza (2012), a forma com que a narrativa é construída: 
É um estilo incômodo que desautomatiza o lugar-comum das ideias de quem lê, de modo que uma descoberta constantemente se inaugura, palavras são inventadas, personagens são surpreendentes, acreditase a todo o momento haver decifrado um mistério, mas o sentimento em seguida se frustra; crê-se piamente na superfície até que uma série de desdobramentos ficcionais se revele. (p.2)

O final, da forma como se apresenta, em $O$ Mistério do Coelho Pensante, coaduna-se com o tom de conversa proposto pela autora para a narrativa, visto que se converte em um momento que convoca a participação do pequeno leitor para a elaboração de uma resposta para o problema. Além disso, como já expomos anteriormente incentiva o diálogo com o mediador já convocado na apresentação do livro: "Peço desculpas a pais e mães, tios e tias, e avós, pela contribuição forçada que serão obrigados a dar [...]. C. L." (1999, s/p.).

\section{CONSIDERAÇÕES FINAIS}

Como pudemos perceber a partir deste trabalho, $O$ Mistério do Coelho Pensante é uma obra que foge dos personagens estereotipados, dos lugares comuns, contando com elementos estéticos não triviais para o período em que a obra fora escrita e publicada, em razão da presença de elementos, até então, pouco empregados na literatura 
infantil brasileira: como a oralidade marcada pelo diálogo com o pequeno leitor, o final aberto, além da metaficção e do narrador não onisciente.

De acordo com o que aqui apresentamos, mesmo partindo de uma experiência real, a história foi criada casualmente fruto de um pedido do filho da autora, Paulo -, e, também por acaso, tornou-se um livro. Todavia, não foi acidental o fato ter sido considerado um d'Os melhores de 67. O Prêmio Troféu Crianças confirmou o que já se sabia acerca da sua literatura destinada ao público adulto, a engenhosidade da sua escrita.

\section{REFERÊNCIAS}

BICHUETTE, Stela de Castro; COELHO, Sueli Braz (2014). "O mistério do coelho pensante e a ausência da literatura infantil de Clarice Lispector da historiografia literária brasileira". Soletras, 28, 214-228.

COLOMER, Teresa (2017). Introdução à literatura infantil e juvenil. Laura Sandroni (Trad.). São Paulo: Global.

CORREIO DA MANHÃ (1971). "Matéria sobre Clarice Lispector". Anexo, 2 nov., p.2.

DIÁRIO DE NOTÍCIAS (1968). "Matéria sobre Clarice Lispector". 4 fev., p.12. DINIZ, Nilson Fernandes (2001). Perto do coração criança: uma leitura da infância nos textos de Clarice Lispector. (Tese - Doutorado em Educação). Universidade Estadual de Campinas, Campinas.

DUARTE, Cristina Rothier (2019). A literatura infantil brasileira do século XIX: adaptações para crianças em Contos da Carochinha, de Figueiredo Pimentel. (Dissertação - Mestrado em Letras). Universidade Federal da Paraíba, João Pessoa. 
FRISON, Samuel (2014). “Clarice Lispector: oralidade, fabulação e recriação em Doze Lendas Brasileiras - Como nasceram as estrelas - Doze Lendas Brasileiras". Boitatá, 9(17), 284-296.

GANCHO, Cândida Vilares (2001). Como analisar narrativas. 7.ed. São Paulo: Editora Ática.

GUIMARÃES, Mell Sauter Brites (2017). "As infâncias de Clarice Lispector: estudo da construção literária da infância em contos adultos e infantis". Dissertação (Mestrado em Letras). Universidade de São Paulo, São Paulo. HILA, Cláudia Valéria Doná (2004). “Desfechos para narrativas: rompendo paradigmas". Anais da XV Semana de Letras, Universidade Estadual de Maringá, Maringá-PR. In http://www.escrita.uem.br/escrita/pdf/cvdhila1. pdf Acesso em 11.Out.2019.

IVAN, Maria Eloísa de Souza (2010). "O narrador, a metalinguagem e o espelho refletido". Nucleus, 1(1), 39-48.

JORNAL DO BRASIL (1968). "Matéria sobre 'os melhores de 67'”. 31 jan., p.17.

(1967). "Matéria sobre Clarice Lispector". 30 Out., p.2.

JORNAL DO COMMERCIO (1973). "Entrevista com Clarice Lispector". Segundo caderno, 9 set., p.5.

LAJOLO, Marisa; ZILBERMAN, Regina (1984). Literatura infantil brasileira: história \& histórias. São Paulo: Ática.

LISPECTOR, Clarice (1999). O mistério do coelho pensantes. Mariana Massarani (llustr.). Rio de Janeiro: Rocco.

(2017). A mulher que matou os peixes. Mariana Valente (llustr.). Rio de Janeiro: Rocco Pequenos Leitores.

SOUSA, Douglas Rodrigues de (2017). "O mistério da literatura infantil de Clarice Lispector: projeto estético, inovação e criação". Revista Travessias, 11(2), 10-26.

SOUZA, Flávia Alves Figueirêdo (2012). "Clarices, casinholas, coelhos e aporias". REEL-Revista Eletrônica de Estudos Literários, 10. 
Cristina Rothier Duarte é Mestre em Literatura pelo Programa de PósGraduação em Letras da UFPB (2019). Doutoranda bolsista da CAPES pelo mesmo Programa. Atua em pesquisas relacionadas à Formação inicial docente, Ensino de Literatura e História da Literatura Infantil brasileira. É participante dos Grupos de Pesquisas LEL - Leitura, Ensino de Literatura e TecnologianaEducação(IFPB)eGEEF-GrupodePesquisaem Estágio, Ensino e Formação Docente, linha Leitura, Literatura infantil, juvenil e ensino. E-mail: cristinarothier@hotmail.com.

ORCID iD: http://orcid.org/0000-0002-4183-7435

Girlene Marques Formiga é Doutora em Letras pelo pelo Programa de Pós-Graduação em Letras da UFPB (2009) e Mestre pelo mesmo Programa (2004) na área de Linguagem e Ensino. Atua como professora do Instituto Federal de Educação, Ciência e Tecnologia da Paraíba desde 1995. É docente na Licenciatura em Letras com habilitação em Língua Portuguesa e no Programa de Pós-Graduação em Educação Profissional e Tecnológica. Tem interesse por temas relacionados ao Ensino, Ensino de literatura, à História da leitura, Leitura literária, Literatura infantil e juvenil, em perspectivas sócio-histórico-culturais. É líder do grupo de pesquisa LEL - Leitura, Ensino de Literatura e Tecnologia (IFPB). Divide a liderança do Grupo Tecnologias colaborativas no ensino e redes aprendentes na educação profissional na linha Práticas educativas na Educação Profissional e Tecnológica. Integra ainda o GEEF - Grupo de Pesquisa em Estágio, Ensino e Formação Docente (UFPB), atuando na linha Leitura, Literatura infantil, juvenil e ensino. E-mail: girlene.formiga@ifpb.edu.br.

ORCID iD: http://orcid.org/0000-0002-4988-7699 